\title{
Mass Release of Trichogramma evanescens and T. cacoeciae Can Reduce Damage by the Apple Codling Moth Cydia pomonella in Organic Orchards under Pheromone Disruption
}

\author{
Lene Sigsgaard ${ }^{1}$, Annette Herz ${ }^{2}$, Maren Korsgaard ${ }^{3}$ and Bernd Wührer ${ }^{4, *}$ \\ 1 Department of Plant and Environmental Sciences, University of Copenhagen, Thorvaldsensvej 40, \\ DK-1871 Frederiksberg C, Denmark; les@plen.ku.dk \\ 2 Julius Kühn Institut, Heinrichstraße 243, Annette, D-64287 Darmstadt, Germany; \\ Annette.Herz@julius-kuehn.de \\ 3 Ecoadvice, Gefion, Fulbyvej 15, DK-4180 Sorø, Denmark; mak@ecoadvice.dk \\ 4 AMW Nützlinge GmbH, Ausserhalb 54, D-64319 Pfungstadt, Germany \\ * Correspondence: wuehrer@amwnuetzlinge.de
}

Academic Editor: Brian T. Forschler

Received: 2 November 2016; Accepted: 29 March 2017; Published: 4 April 2017

\begin{abstract}
Cydia pomonella is a major pest in apples in Denmark. Trichogramma spp. are known biocontrol agents of $C$. pomonella eggs and two naturally occurring species in Denmark, which are also both commercially available, were chosen for mass-release trials. Trichogramma evanescens, T. cacoeciae or a mix of the two species were evaluated for mass-release to control C. pomonella in two commercial organic apple orchards, one in 2012 and one in 2013, using a complete randomized block design. Pheromone disruption was used in both orchards, making the study one of the first to evaluate Trichogramma release under a mating disruption regime. Trichogramma activity was assessed using bait cards with Sitotroga cerealella eggs. The percent $C$. pomonella damaged fruit was recorded and the fruit yield was estimated. In 2012 cool and wet weather conditions resulted in low Trichogramma activity $(<16 \%$ bait cards parasitized) and only T. evanescens was recovered from bait cards. The conditions in 2013 were warmer but $T$. evanescens was still $>10$ times more frequently found in bait cards than T. cacoeciae. There was a significant effect of the treatment and year $(p=0.009)$ and of the sampling period ( $p=0.0008$ ) on Trichogramma activity (proportion bait cards parasitized), with no significant difference between treatments in 2012. In 2013 the highest activity was found in T. evanescens and mixed treatments, in July reaching $69 \%$ and $47 \%$ bait cards parasitized, respectively. Fruit damage was highest in the control plots $(7.1 \%)$ compared with Trichogramma treatments (T. evanescens $2.8 \%$, T. cacoeciae $3.8 \%$, mixed $3.3 \%)(p=0.028)$. Yield did not differ significantly between treatments. In conclusion, Trichogramma mass release is a promising biocontrol method for use in the Danish climate, but further studies are needed regarding the performance of the two Trichogramma species (and potential other Trichogramma species) towards C. pomonella eggs in the field to identify the best biocontrol candidate.
\end{abstract}

Keywords: Trichogramma evanescens; Trichogramma cacoeciae; Cydia pomonella; biological control; organic production

\section{Introduction}

Denmark has $22.3 \%$ of its apple under organic production [1], and a steadily increasing demand for organic foods, with a demand for fruit alone increasing by 19\% from 2013-2014 [2]. Pests and diseases cause quality and yield reductions in organic apples, with yields of grade A apples of about a 
third of conventional producers. In order to obtain stable or higher yields, control of pests is essential. The codling moth Cydia pomonella (L.) (Lepidoptera: Tortricidae) is a primary pest of apple, and in organic production, the options for its control are cultural control, conservation biological control and, since 2011, mating disruption and C. pomonella granulosis virus (CpGV) have been permitted. Since 2011, mating disruption has been used in most organic orchards, while few organic growers use CpGV. [3]. Trichogramma spp. parasitoids are important biological control agents worldwide and in Europe [4,5]. In orchards, T. dendrolimi Matsumura and T. cacoeciae (Marchal) are used to control C. pomonella [6,7]. Other Trichogramma species used in controlling this pest are T. platneri Nagarkatti [8], T. minutum Riley, and T. pretiosum Riley $[7,9-11]$ in the United States. Recently T. evanescens Westwood, which occurs naturally in orchards, has become available for C. pomonella control in a mixture with T. cacoeciae [12].

Trichogramma evanescens and T. cacoeciae were selected for mass-release trials. Both species occur naturally in Denmark and are known to frequently parasitize the codling moth C. pomonella [13]. T. evanescens is relatively cold-hardy $[14,15]$ and has higher fecundity than T. cacoeciae $[13,15]$. A mix of T. cacoeciae and T. dendrolimi is used with good results in small privately owned orchards in Germany, with only 5 ha commercial orchards officially treated [16]. Currently, the price of Trichogramma spp. is considered too high for use in commercial conventional orchards and Trichogramma's sensitivity to sulfur, regularly used in organic orchards, is a concern. Due to a lack of alternatives, Danish organic growers are motivated to get more options to control $C$. pomonella. The present study was done to assess the potential of egg parasitoids of the genus Trichogramma for the control of $C$. pomonella, when applied in organic orchards using mating disruption. We hypothesized that mass release of Trichogramma would be able to reduce the proportion of apples with C. pomonella damage, and that the two selected Trichogramma species would both be able to perform under Danish weather conditions, possibly with the better performance of one of the species or of the species mixture.

\section{Materials and Methods}

\subsection{Orchards}

Experiments were conducted in two commercial organic orchards, one in 2012 in Høng, and one in 2013 in Kagerup, Regstrup, Holbæk. Both orchards are situated in the Central-Western part of the island of Zealand, Denmark (Høng: $55.363^{\circ} \mathrm{N}, 11.3037^{\circ} \mathrm{E}$, Kagerup: $55.633^{\circ} \mathrm{N}, 11.566^{\circ} \mathrm{E}$ ). Trees in both orchards were planted in 2006. In Høng the trees in all four blocks (experimental design described in Section 2.3) were the variety 'Holsteiner Cox'. In Kagerup, the varieties were 'Holsteiner Cox', 'Alkmene' and two blocks of 'Red Aroma'. Orchards were selected based on codling moth infestation in previous years and appropriate dimensions for a block trial. In 2011, both orchards had about $10 \%$ damaged apples due to C. pomonella, and the orchard in Høng was selected for the study in 2012. In 2012 infestations were low, but some infestation was observed in Kagerup, and this orchard was selected for study in 2013. Thermo loggers were used to record temperature in the orchards, and climate data were obtained from the University of Copenhagen (UCPH) climate station on its experimental farm in Taastrup $\left(55.668^{\circ} \mathrm{N}, 12.305^{\circ} \mathrm{E}\right)$. In Denmark, there is only one annual generation of $C$. pomonella. Both orchards in both years of study used pheromone mating disruption of C. pomonella (2012: Exosec $\mathrm{CM}^{\circledR}$; 2013: Isomate $\mathrm{CLR}^{\circledR}$ ).

Experiments were initiated with the onset of $C$. pomonella oviposition according to pheromone trap captures of the first males and by an early warning from an interactive Decision Support System for pest and disease management in fruit RIMpro [17].

\subsection{Trichogramma Spp. and Bait Cards}

The Trichogramma were received as pupae in Sitotroga cerealella Olivier (Lepidoptera: Gelechiidae) eggs on folded Trichocards (TrichoKarte ${ }^{\circledR}$, AMW Nützlinge GmbH, Pfungstadt, Germany). A Trichocard held ca. 3000 eggs of either T. evanescens, T. cacoeciae or a 1:1 mixture of the two species and 
cards were produced to have different parasitoid developmental stages (time since parasitism), which guaranteed continuous hatching of adult parasitoids for more than two weeks. The Trichogramma species were collected in Germany and mass cultures at AMW are frequently renewed. Trichocards were folded and stapled on both sides thus allowing emerging Trichogramma to pass but excluding larger insects or spiders from entering and possibly damaging the Trichogramma pupae. Trichogramma wasps were obtained from AMW Nützlinge $\mathrm{GmbH}$, Pfungstadt where they had been reared in an incubator at $25 \pm 1{ }^{\circ} \mathrm{C}, 70 \% \pm 10 \% \mathrm{RH}$ and a photoperiod of 16:8 (L:D). The wasps were fed on a diet of honey-gelatin. It has been noted that quality of the parasitoid may be compromised after rearing Trichogramma for many generations on an atypical host. Approaches taken to counter this effect include periodically switching the parasitoids to a different host [6] and populations are transferred to C. pomonella eggs for one generation once a year [18].

Bait cards were used to monitor Trichogramma activity and were baited with ca. 3000 three-day-old S. cerealella eggs. Bait cards were also folded cardboard cards. To protect $S$. cerealella eggs from predatory insects, bait cards were also stapled on the sides still allowing the Trichogramma to enter. Until field use, bait cards were stored at $8{ }^{\circ} \mathrm{C}$ and $60 \%$ relative humidity to prevent $S$. cerealella eggs from hatching.

The two Trichogramma species were distinguished by their colour, and the morphology of the antenna of male T. evanescens [19]. T. cacoeciae is a thelytokous species where no males are present.

Results of mass release of Trichogramma may be affected by naturally occurring Trichogramma. Both in 2012 and 2013 bait for Trichogramma was also done in a part of the two orchards without Trichogramma mass release (at least $100 \mathrm{~m}$ away), and in three other orchards on Zealand (Ventegodtgaard, Strandegaard and Kyse) in spring (late May/early June), early summer (late June) and late summer (late July/early August). In 2012 baiting was done with S. cereallela eggs and in 2013 baiting was done with C. pomonella eggs. Since baitings for naturally occurring Trichogramma were unsuccessful, it can be assumed that the natural population was low and would not affect the experiment [20].

\subsection{Experimental Design and Field Assessment}

A randomized complete block (RCB) design with four blocks was used both years. There were four treatments T. evanescens, T. cacoeciae, a 1:1 mixture of the two and a no release control. Each treatment was replicated once per block, the block being a tree-row of one apple variety and blocks were separated by at least one tree-row. Treatment plots within each block were $20 \mathrm{~m}$ long equivalent to 18 trees and with at least five trees between treatments. In each treatment plot, except control plots, a Trichocard was placed on every third tree (6 Trichocards per treatment plot). They were placed 1.5-2 $\mathrm{m}$ high on a branch $30-80 \mathrm{~cm}$ from the trunk. Trichocards were fixed to the branch by green twine. In 2012 Trichocards were set out three times with ca. three weeks interval on 4 June, 24 June and 17 July. In 2013 Trichocards were only set out twice, on 17 June and 5 July. Eight Trichocards for each treatment were checked for hatch and Trichogramma species composition in the laboratory.

In each treatment plot, a bait card with $S$. cereallela eggs was placed on each of eight different trees, avoiding trees with a Trichocard, to record Trichogramma parasitism. Bait cards were labeled by treatment and date and in both years cards were set out on the same day as the Trichocards and collected after $72 \mathrm{~h}$. In 2012 an additional baiting was done 24-27 July where only four bait cards were used per treatment plot. This baiting was done as hardly any parasitism was observed on 20 July 2012, most likely due to rainy and windy weather conditions, and for later statistical analysis data from 20 July 2012 was excluded, leaving three sampling periods for analysis.

Collected bait cards were checked for presence of any arthropods, which were recorded and removed before transport to the lab in a cooling bag with cooling elements maintaining ca. $12{ }^{\circ} \mathrm{C}$. Bait cards were placed individually in Petri-dishes sealed with parafilm, labeled with block and treatment and kept at $20^{\circ} \mathrm{C}, \mathrm{L}: \mathrm{D}$ 16:8 for at least two weeks regularly checking for Trichogramma 
emergence. In a few cases all eggs on a bait card had been eaten, typically if an earwig had entered the bait card. These cards were recorded as missing.

The damage from C. pomonella was identified by entry or exit holes on apples and when needed, such as in cases where holes were by the calyx or stem end of the fruit and hard to detect, the damage was confirmed by dissecting apples. Early in the season holes caused by apple sawfly Hoplocampa testudinea (Klug) may be mistaken for C. pomonella damage, but the damage caused by this pest looks different and apples affected by apple sawfly normally fall off the tree by the so-called "June drop", before our damage assessment. On 19 July 2012 C. pomonella infestation was assessed in all blocks. In each treatment plot, 10 apples from 10 randomly selected trees were visually assessed for C. pomonella damage, ( 400 fruits per treatment for the full four-block experiment). Total yield was assessed on 21 August 2012 from counts of the number of all apples per branch on two randomly selected branches per plot. In 2013, fruit damage was assessed 1 July 2013 and yield was assessed 29 August 2013. This was done as in 2012, but in 2013 damage was assessed on 10 apples from eight randomly selected trees per treatment plot (320 fruits per treatment for the full four-block experiment), and total yield was assessed based on counts of all fruits on eight to 10 branches per treatment plot. In 2013 yield per tree was estimated by multiplying yield per branch by the average number of branches per tree. Mid-season damage assessment before growers start thinning damaged fruit gives a good assessment of the pest pressure. Late damage assessment is underestimating damage as a result of organic growers' careful thinning of damaged fruits. Yield assessment before harvest, on the other hand, gives a better assessment of final harvest.

\subsection{Data Analysis}

The proportion of bait cards with Trichogramma parasitism (irrespective of the number of eggs parasitized) was analysed as it reflects the wasps' ability to disperse, find and parasitize hosts. Proportions were analyzed assuming a binomial distribution using SAS Proc GLIMMIX [21]. The full model included sampling period (week (year)), year, treatment and their interactions, with block as a random factor. The proportion of $T$. cacoeciae of total wasps emerged was used to analyze the relative success of the two species. This was tested in 2013, as in that year both species emerged. Proportions of apples damaged by C. pomonella were analyzed assuming a binomial distribution using SAS Proc GLIMMIX. In the model, the logit of the binomial probability depended on the fixed effects of sampling period week, treatment, and the two-way interaction, with block as a random factor. A Chi-square test was done to compare the proportion of bait cards found by the two species of Trichogramma by treatment and week. Total yield (apples per branch) was square-root transformed prior to analysis and analyzed as a function of treatment, year and the interaction between treatment and year, with block as a random factor using SAS Proc Mixed [21]. Non-significant interaction effects of fixed effects were removed from the final models.

\section{Results}

\subsection{Trichogramma Releases}

The summer of 2012 was cold and wet (average temperatures $( \pm \mathrm{SD})$ and precipitation from the UCPH climate station; June: $14.1 \pm 3.3^{\circ} \mathrm{C}$ and $74 \mathrm{~mm}$, July: $17.6 \pm 3.5^{\circ} \mathrm{C}$ and $60 \mathrm{~mm}$, August $18.2 \pm 3.7^{\circ} \mathrm{C}$ and $32 \mathrm{~mm}$ ), which resulted in low C. pomonella infestation. Trichogramma activity was also low, as determined from parasitism found in bait cards, with only 136 Trichogramma emerging from bait cards across all the four dates of sampling. Only T. evanescens emerged from the bait cards in 2012. The summer of 2013 was warmer and drier (average temperatures $( \pm S D)$ and precipitation from the UCPH climate station; June: $16.3 \pm 3.2^{\circ} \mathrm{C}$ and $48 \mathrm{~mm}$, July: $19.3 \pm 3.7^{\circ} \mathrm{C}$ and $17 \mathrm{~mm}$, August $18.4 \pm 3.4^{\circ} \mathrm{C}$ and $34 \mathrm{~mm}$ ), and C. pomonella infestation was higher, and from the first collection date 20 June, a total of 810 T. evanescens and six T. cacoeciae emerged from all bait cards. T. evanescens continued to be the dominant species found on bait cards (8 July: 1250 T. evanescens and 114 T. cacoeciae emerged). 
There was a significant interaction effect of the treatment and year $\left(F_{3,66}=4.23, p=0.009\right)$ and a significant main effect of the sampling period (week(year) $\left(F_{2,66}=6.28, p=0.0008\right)$ on the proportion of parasitized bait cards (Figure 1). Pairwise comparisons of ls-means showed no significant differences between treatments in 2012, while in 2013 the highest parasitism was found in T. evanescens and mixed treatments, with $T$. evanescens higher than the mixed treatment, but not statistically significantly $(t=1.87, p=0.066)$. The $T$. cacoeciae treatment was not significantly different from the control. In 2012, the proportion of bait cards parasitized was significantly higher in the first sampling period $(7.6 \%)$ than the last sampling period $(2.0 \%)(t=2.07, p=0.042)$, while the intermediate period was not different from the other two periods (5.5\%). In 2013 the proportion of cards parasitized in the first period was less than half $(19.2 \%)$ of the second sampling period $(43.4 \%)(t=-3.81, p=0.0003)$. In 2013 both T. evanescens and T. cacoeciae emerged from bait cards, and there was a significant effect of the treatment and period on the proportion of bait cards found by T. cacoeciae with a higher proportion emerging in the T. cacoeciae treatment and more in July, but no interaction effect of the treatment and period. From the first to second sampling period in 2013, the proportion of cards found by $T$. cacoeciae increased from $0.64 \%$ to $6.62 \%\left(F_{16,28.2}=28.8, p<0.0001\right)$. The proportion of cards found by $T$. cacoeciae was highest in the T. cacoeciae treatment $(18.4 \%)$, intermediate in the mixed treatment $(4.7 \%)$ and low in the T. evanescens $(0.2 \%)$ and control $(0.1 \%)$ treatments. The proportion of bait cards found by T. evanescens was significantly higher in all treatments except the T. cacoeciae treatment (Figure 1).

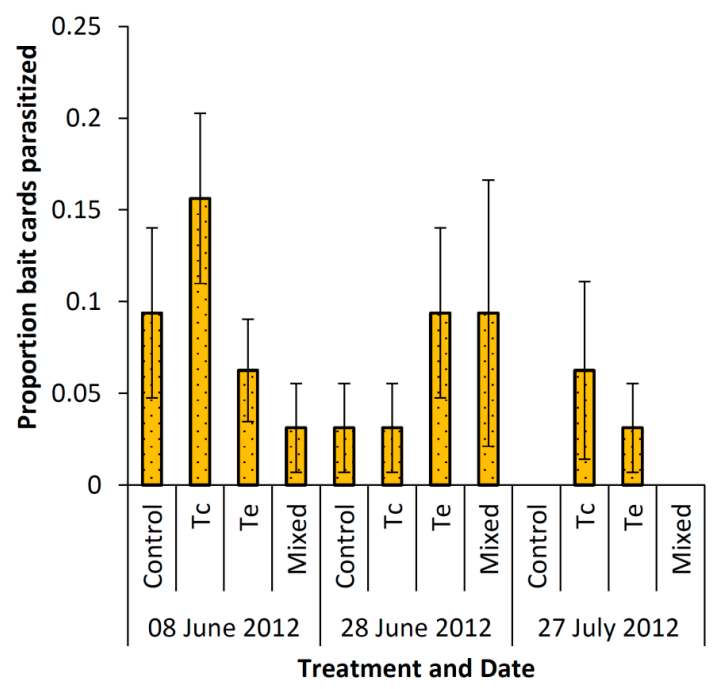

(a)

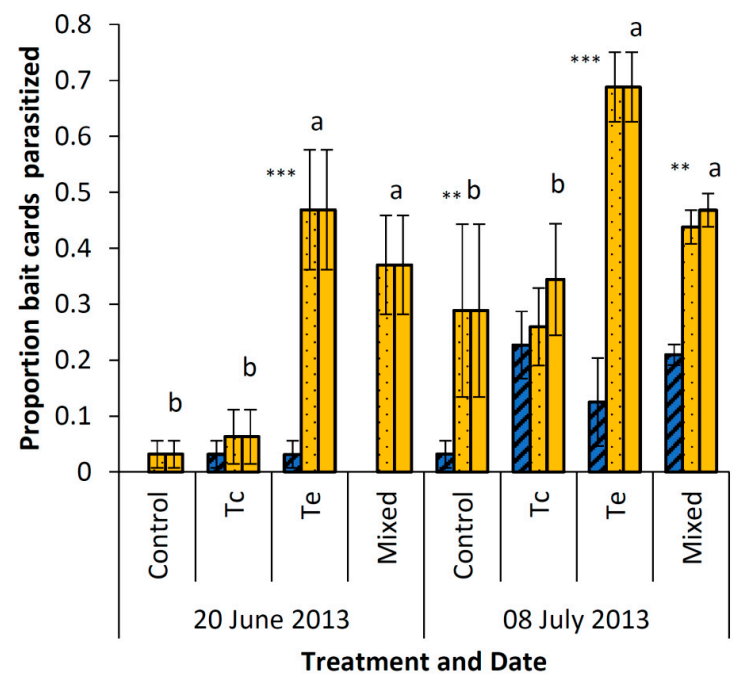

(b)

Figure 1. Trichogramma activity assessed as mean proportion $( \pm \mathrm{SE})$ of bait cards being parasitized with Trichogramma evanescens (orange and dotted), T. cacoeciae (blue and hatched) and the total proportion bait cards being parasitized (purple) in a completely randomized block experiment with three treatments; mass release using Trichocards ${ }^{\circledR}$ of T. evanescens (Te), T. cacoeciae (Tc), a mix of the two species (Mixed) and a control in (a) 2012, where only T. evanescens emerged and no significant differences were found between treatments; (b) in 2013 where both species emerged. Letters indicate significant differences between total proportion bait cards parasitized based on pairwise comparisons of ls-means. Asterisks indicate significant differences (Chi-square test, ${ }^{*} p<0.05$, ${ }^{* *} p<0.01,{ }^{* * *} p<0.001$ ) between proportion cards found by the two species within a treatment.

A laboratory check in 2013 of eight Trichocards, with T. cacoeciae, T. evanescens and a mix of the two species, showed that T. cacoeciae cards produced an average of $1737.5 \pm 69.5$ parasitoids of which $99.7 \% \pm 4.0 \%$ were $T$. cacoeciae. For $T$. evanescens cards, $1475.0 \pm 55.9$ wasps hatched of which $100 \% \pm 3.8 \%$ were T. evanescens. From the mixed Trichocards, $1975 \pm 50.8$ parasitoids hatched of which $54.6 \% \pm 2.6 \%$ were T. evanescens (males and females) and $45.4 \% \pm 2.6 \%$ T. cacoeciae (only females). Plots were as large as the orchard size permitted $(20 \mathrm{~m}$ long and separated from other treatments, see 
details in Section 2.3), but in 2013, after the second augmentative release, the proportion of the bait cards found by T. evanescens was $26 \%$ and $29 \%$ in the T. cacoeciae and control treatments, respectively, indicating the dispersal of T. evanescens to these plots.

\subsection{Fruit Damage and Yield}

The effect of treatment on fruit damage was significant $\left(F_{3,27}=3.55, p=0.028\right)$, with a higher percent of damaged apples in the control $(7.1 \% \pm 3.4 \%)$ than in Trichogramma treatments (T. evanescens $(2.8 \% \pm 1.5 \%)(t=-2.73, \mathrm{df}=27, p=0.01)$, mixed $(3.8 \% \pm 1.9 \%)(t=-2.12, \mathrm{df}=27, p=0.04)$, and T. cacoeciae $(3.3 \% \pm 1.8 \%)(t=2.32, \mathrm{df}=27, p=0.03))$ (Figure 2$)$. Fruit damage was significantly higher in $2013(5.7 \% \pm 2.7 \%)$ than in $2012(2.8 \% \pm 1.4 \%)\left(F_{1,27}=7.66, p=0.010\right)$, but there was no interaction effect between the damage and year.

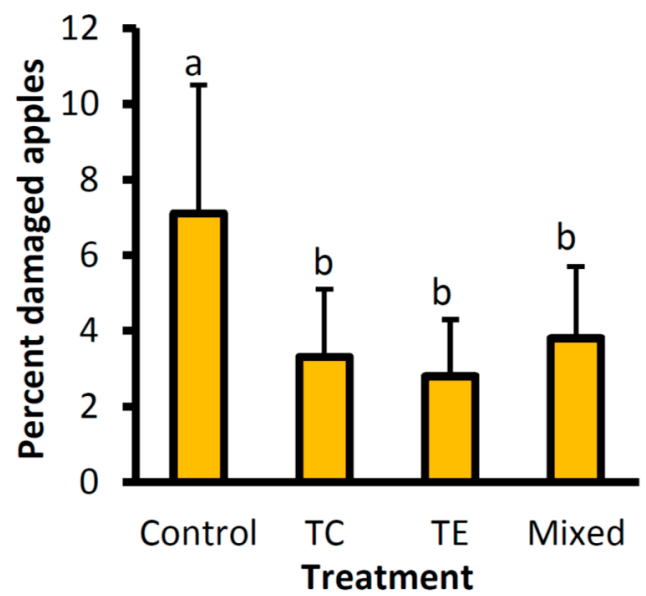

Figure 2. Average percent apples damaged by C. pomonella $( \pm \mathrm{SE})$ in a completely randomized block experiment with four treatments; mass release using Trichocards ${ }^{\circledR}$ of T. evanescens (Te), T. cacoeciae (Tc), a mix of the two species (Mixed) and a control for years 2012 and 2013.

In both years the total yield was estimated as apples per branch. In 2012 the total yield was: apples/branch: T. evanescens $1.6 \pm 0.6$ apples, T. cacoeciae $2.4 \pm 0.5$ apples, mixed $1.8 \pm 0.8$ apples and control $1.6 \pm 0.4$ apples. The total yield by late August 2013 was also estimated for whole trees. The estimated yield per branch (and per tree) in 2013 was: T. evanescens $3.62 \pm 1.33(76.45 \pm 42.10)$ apples, T. cacoeciae $3.89 \pm 1.30(53.99 \pm 24.55)$ apples, mixed $2.78 \pm 0.72(77.98 \pm 44.50)$ apples and control $3.12 \pm 0.78(48.17 \pm 22.95)$ apples. There was no significant difference between treatments $\left(F_{3,24}=0.19, p=0.90\right)$ or years $\left(F_{1,24}=0.04, p=0.83\right)$ in terms of the total yield.

\section{Discussion}

In both the 2012 and 2013 treatments, the T. evanescens and mixture of T. evanescens and T. cacoeciae showed higher parasitoid activity as measured by the proportion of bait cards parasitized. T. evanescens was dominant among emerging wasps, and the Trichogramma species mixture treatment did not improve parasitism on bait cards. The difference in the performance of the two Trichogramma species may suggest that T. evansescens is better adapted to the Danish climate, as T. cacoeciae performs well against $C$. pomonella in Germany, where the summer temperatures are higher (average temperatures in Frankfurt, Germany, ca. $800 \mathrm{~km}$ south of our field sites: June $17.3^{\circ} \mathrm{C}$, July $19.5^{\circ} \mathrm{C}$, August $19.1{ }^{\circ} \mathrm{C}$ ). In 2013 the proportion of T. cacoeciae found in bait cards increased as the season progressed and temperatures increased. Regional differences in Trichogramma performance are also known from the US, where mass release of the native T. platneri outperformed three other Trichogramma species [11], even the arboreal species Trichogramma minutum, which is indigenous to the eastern US $(3500 \mathrm{~km}$ distance). The author suggests its performance may have been compromised by the much drier climate 
of California [11]. It is, however, also possible that bait cards with Sitotroga eggs were more attractive to T. evanescens than to T. cacoeciae and therefore T. evanescens might prevail in this experimental design. However, no other method for measuring parasitoid activity was feasible because codling moth density was very low and egg parasitism could not be assessed directly.

All treatments with Trichogramma had significantly lower damage than the control, though observed damage was low. Growers in Danish organic orchards are very keen on sanitizing the orchard by hand, removing any fruit with signs of disease or insect attack such as C. pomonella, as alternatives for control are few, so results provided a conservative estimate of $C$. pomonella infestation in the orchards. Both orchards in both years of study used mating disruption of C. pomonella since this became allowed in 2011, which most likely reduced C. pomonella infestation.

Damage reduction is equivalent to the $50 \%-70 \%$ reported from other studies [4,18], and the damage level of $1 \%-3 \%$ is equivalent to that reported from other studies. For conventional apples $<1 \%$ damaged by C. pomonella is accepted, but the result of Trichogramma release still shows that a large improvement over the current situation can be obtained in organic orchards. Damage assessment is difficult as it will be influenced by growers' hand thinning of infested fruits. A late assessment of damage provided very low damage and is not included here. Thus our comparisons of damage between treatments are based on assessments made in July, before most hand thinning of the fruit was done. For future studies, an assessment of the proportion of damaged fruit removed during hand thinning should be done, and if possible, including more than one orchard per year would also improve, to some extent, the scientific accuracy.

A difference in the total yield assessed could occur as a result of infested fruit dropping from the trees, and other infested fruit being removed by hand thinning. However, the total yield was not significantly different between treatments, and variation was very large. Factors other than C. pomonella such as any other pests or diseases as well as orchard management would have affected yield, contributing to the variability of the results.

The results show that Trichogramma mass release against C. pomonella can be successfully used in orchards where mating disruption is also used.

\section{Conclusions}

In conclusion, Trichogramma mass release is a promising strategy for use in the Danish climate. In cool years, such as 2012, augmentative releases of Trichogramma will be unnecessary as C. pomonella infestation remains low, while in warmers years, such as in 2013, results obtained with Trichogramma treatments are equivalent to results from studies of other Trichogramma species elsewhere $[4,18,22,23]$. Results show that Trichogramma mass release can be successfully used in orchards in which the mating disruption of C. pomonella is also used. Release may be guided by the orchards' history of infestation with C. pomonella, and timing of releases can be decided based on the pests' phenology. Though T. evanescens was more active on bait cards, damage assessment showed no significant difference between the three Trichogramma treatments. However, it may be possible to identify Trichogramma species or strains better adapted to cool climates in Northern Europe. Though the price of Trichogramma is high compared to insecticide, it provides an important alternative for organic pome fruit growers, and with increasing environmental awareness and stricter regulations, it becomes increasingly important for plant producers that biological control methods are available and documented in field trials.

Acknowledgments: The study was funded by the Danish Food Industry Agency's Organic Research, Development, and Demonstration program. We gratefully acknowledge the contribution by three anonymous reviewers.

Author Contributions: Lene Sigsgaard conceived, designed and performed the experiments in dialogue with Annette Herz, Bernd Wührer and Maren Korsgaard. Lene Sigsgaard analyzed the data; Bernd Wührer contributed with rearing insects and Maren Korsgaard assisted in monitoring C. pomonella; Lene Sigsgaard wrote the first draft of the paper which was then revised with the three co-authors.

Conflicts of Interest: The authors declare no conflict of interest. The founding sponsors had no role in the design of the study; in the collection, analyses, or interpretation of data; in the writing of the manuscript, and in the decision to publish the results. 


\section{References}

1. Naturerhvervsstyrelsen. Statistik over økologiske jordbrugsbedrifter 2015. In Autorisation E Produktion; Naturerhversstyrelsen, Ministry of Environment and Food of Denmark: Copenhagen, Denmark, 2016.

2. Danmarks Statistik. Detailomsætningen af økologiske fødevarer 2014. In Nyt Fra Danmarks Statistik; Danmarks Statistik: Copenhagen, Denmark, 2015; Volume 195, p. 2.

3. Axelsen, J.A.; Munk, L.; Sigsgaard, L.; Ørum, J.E.; Streibig, J.C.; Navntoft, S.; Christensen, T.; Pedersen, A.B.; Elkjær, K.; Korsgaard, M.; et al. Udredning Om Moniterings, Varslings-Og Beslutningsstøttesystemer for Skadevoldere I Planteproduktionen I Landbrug, Gartneri og Frugtavl; Miljøstyrelsen: Copenhagen, Danmark, 2012.

4. Hassan, S.A. The mass rearing and utilization of Trichogramma to control lepidopterous pests-Achievements and outlook. Pestic. Sci. 1993, 37, 387-391. [CrossRef]

5. Zimmermann, O. Der Einsatz von Trichogramma-Schlupfwespen in Deutschland. Gesunde Pflanz. 2004, 56, 157-166. [CrossRef]

6. Smith, S.M. Biological control with Trichogramma: Advances, successes, and potential of their use. Annu. Rev. Entomol. 1996, 41, 375-406. [CrossRef] [PubMed]

7. Samara, R.Y.; Monje, J.C.; Zebitz, C.P.W. Comparison of different European strains of Trichogramma aurosum (Hymenoptera: Trichogrammatidae) using fertility life tables. Biocontrol Sci. Technol. 2008, 18, 75-86. [CrossRef]

8. Mansfield, S.; Mills, N.J. Host egg characteristics, physiological host range, and parasitism following inundative releases of Trichogramma platneri (Hymenoptera: Trichogrammatidae) in walnut orchards. Environ. Entomol. 2002, 31, 723-731. [CrossRef]

9. Yu, D.; Hagley, E.; Laing, J. Biology of Trichogramma minutum Riley collected from apples in southern ontario. Environ. Entomol. 1984, 13, 1324-1329. [CrossRef]

10. Dolphin, R.; Cleveland, M.; Mouzin, T.; Morrison, R. Releases of Trichogramma minutum and T. cacoeciae in an apple orchard and the effects on populations of codling moths. Environ. Entomol. 1972, 1, 481-484. [CrossRef]

11. Mills, N. Augmentation in orchards: Improving the efficacy of Trichogramma inundation. In Proceedings of the 1st International Symposium on Biological Control of Arthropods, Honolulu, HI, USA, 14-18 January 2002; USDA Forest Service FHTET-03-05. 2003; pp. 130-135.

12. Kienzle, J.; Zimmermann, O.; Wührer, B.; Triloff, P.; Morhard, J.; Landsgesell, E.; Zebitz, C. New species and new methods of application-A new chance for Trichogramma in codling moth control? In Pcoceedings of the Ecofruit. 15th International Conference on Organic Fruit-Growing, Hohenheim, Germany, 20-22 February 2012; pp. 317-321.

13. Polaszek, A. Species diversity and host associations of Trichogramma in Eurasia. In Egg Parasitoids in Agroecosystems with Emphasis on Trichogramma; Springer: New York, NY, USA, 2009; pp. 237-266.

14. Boivin, G. Overwintering strategies of egg parasitoids. In Biological Control with Egg Parasitoids; Wajnberg, S.A., Ed.; Hassan, CAB International: Wallingford, UK, 1994; pp. 219-244.

15. Schöller, M.; Hassan, S.A. Comparative biology and life tables of Trichogramma evanescens and T. cacoeciae with Ephestia elutella as host at four constant temperatures. Entomol. Exp. Appl. 2001, 98, 35-40.

16. Jehle, J.A.; Herz, A.; Keller, B.; Kleespies, R.G.; Koch, E.; Larem, A.; Schmitt, A.; Stephan, D. Statusbericht Biologischer Pflanzenschutz 2013. In Berichte aus dem Julius Kühn-Institut; Julius Kühn Institute: Darmstadt, Germany, 2014; Volume 173, p. 121.

17. Trapman, M.; Helsen, H.; Polfliet, M. Development of a dynamic population model as a decision support system for codling moth (Cydia pomonella) management. In Proceedings of the Ecofruit-13th International Conference on Cultivation Technique and Phytopathological Problems in Organic Fruit-Growing, Weinsberg, Germany, 18-20 February 2008; pp. 247-251.

18. Hassan, S.A.; Kohler, E.; Rost, W.M. Mass-production and utilization of Trichogramma 10. Control of the codling moth Cydia pomonella and the summer fruit tortrix moth Adoxophyes orana Lep, Tortricidae. Entomophaga 1988, 33, 413-420. [CrossRef]

19. Pintureau, B. Les Espèces Européennes de Trichogrammes; ILV, Ed.; LibroVeritas: Cergy-Pontoise, France, 2008.

20. Sigsgaard, L.; University of Copenhagen, Thorvaldsensvej 40, 1871 Frederiksberg C., Denmark. Personal Observation, 2013.

21. SAS Institute. Sas 9.4 Output Delivery System: User's Guide; SAS Institute: Cary, NC, USA, 2014. 
22. Hassan, S.A. Selection of suitable Trichogramma strains to control the codling moth Cydia pomonella and the 2 summer fruit tortrix moths Adoxophyes orana, Pandemis heparana Lep, Tortricidae. Entomophaga 1989, 34, 19-27. [CrossRef]

23. Hassan, S.A.; Hafes, B.; Degrande, P.E.; Herai, K. The side-effects of pesticides on the egg parasitoid Trichogramma cacoeciae Marchal (Hym., Trichogrammatidae), acute dose-response and persistence tests. J. Appl. Entomol. 1998, 122, 569-573. [CrossRef]

(c) (1) (C) 2017 by the authors. Licensee MDPI, Basel, Switzerland. This article is an open access article distributed under the terms and conditions of the Creative Commons Attribution (CC BY) license (http:/ / creativecommons.org/licenses/by/4.0/). 